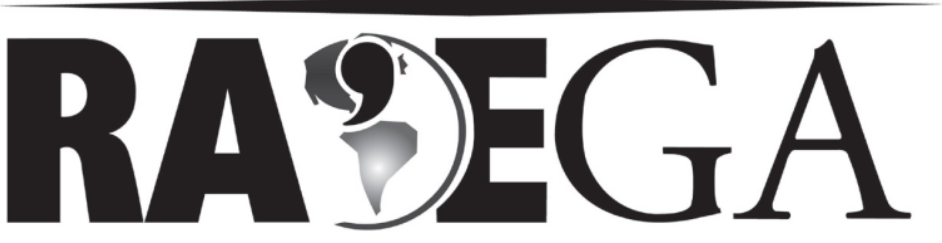

O ESPAÇO GEOGRÁFICO EM ANÁLISE

\title{
DO PLANEJAMENTO AO ORDENAMENTO TERRITORIAL: ESTUDO DA REGIÃO COSTA OESTE DO PARANÁ
}

\section{From planning to land use planning: a study of the west coast region of Paraná}

\author{
Adriana Eliane Casagrande ${ }^{1}$ \\ Edson Belo Clemente de Souza ${ }^{2}$
}

\section{RESUMO}

O presente trabalho tem por objetivo analisar o papel do planejamento, tendo em perspectiva o ordenamento do território na região Costa Oeste do Paraná. Para a realização deste trabalho foram analisados alguns indicadores socioeconômicos fornecidos pelo Instituto Brasileiro de Geografia e Estatística (IBGE), pelo Instituto Paranaense de Desenvolvimento Econômico e Social (IPARDES) e Itaipu Binacional, tais como o Fundo de Participação dos Municípios (FPM), Imposto sobre Circulação dos Municípios (ICMS), Índice de Desenvolvimento Humano por Município (IDH-M) e royalties. Com ênfase no planejamento e no ordenamento territorial, analisou-se se esses indicadores têm evidenciado socioeconomicamente os municípios dessa região.

Palavras-chave: Região Costa Oeste do Paraná; planejamento urbano e regional; ordenamento territorial.

\section{ABSTRACT}

The present work aims to analyze the role of planning, taking into perspective the land use planning in the West Coast Region of Paraná. . To carry out this work, some socioeconomic indicators were analyzed. These indicator were provided by the Brazilian Institute of Geography and Statistics (IBGE), Paraná

\footnotetext{
${ }^{1}$ Mestranda em Geografia pela Universidade Estadual do Oeste do Paraná (Unioeste). Pesquisadora do Laboratório de Estudos Regionais (Laber) e do Grupo de Estudos Fronteiriços (GEF). Marechal Cândido Rondon-PR, Brasil. E-mail: adri_casagrande@yahoo.com.br

2 Professor Associado da Universidade Estadual do Oeste do Paraná (Unioeste). Pesquisador do CNPq. Líder do Grupo de Estudos Fronteiriços (GEF) e membro do Laboratório de Estudos Regionais (Laber). Marechal Cândido Rondon-PR, Brasil. E-mail: ebelo2003@yahoo.com.br
} 
Institute of Economic and Social Development (IPARDES) and the Itaipu Binational, such as the Municipal Participation Fund (FPM), Tax on the Circulation of Municipalities (ICMS), Human Development Index by Municipality (HDI-M) and royalties. With an emphasis on planning and land use planning, it was examined whether these indicators have socioeconomic shown the municipalities of this region.

Keywords: West Coast Region of Paraná; urban and regional planning, land use planning.

\section{INTRODUÇÃO}

O presente artigo tem por objetivo analisar o papel do planejamento na perspectiva do ordenamento do território na região Costa Oeste do Paraná, Figura 1, considerando alguns indicadores socioeconômicos fornecidos pelo Instituto Brasileiro de Geografia e Estatística (IBGE), Instituto Paranaense de Desenvolvimento Econômico e Social (IPARDES) e Itaipu Binacional, tais como: Fundo de Participação dos Municípios (FPM), Imposto sobre Circulação dos Municípios (ICMS), Índice de Desenvolvimento Humano por Município (IDH-M) e royalties.



Figura 1. Localização da Região Costa Oeste do Paraná. Fonte: Maicol Rafael Bade e Adriana Eliane Casagrande. 
Esta região se destaca no plano das relações internacionais, devido à sua localização na faixa de fronteira com o Paraguai. Por esta razão, a região Costa Oeste é marcada por inúmeras particularidades e está envolvida em uma relação socioespacial diferenciada, expressa nos fluxos econômicos dos povos fronteiriços.

A região Costa Oeste do Paraná surge a partir da construção da Usina Hidrelétrica de Itaipu (1970-1991) e a formação do Lago de Itaipu (1982). Os municípios que foram atingidos pelo lago sofreram grandes impactos, principalmente no que concerne a reconfiguração do território, novas configurações socioespaciais, modificando a paisagem e as relações econômicas estabelecidas na região.

Uma região é estabelecida a partir da produção do espaço, da interação entre a sociedade e a natureza, pelas relações sociais estabelecidas, com especial destaque para o papel das grandes empresas e do Estado, com suas iniciativas de "criação de regiões" (HAESBAERT, 2005).

Assim, a região, enquanto um recorte espacial é definida a partir de sua coerência interna, de sua especificidade. Apesar da globalização dita homogeneizadora, com a unificação dos mercados e economia capitalista de padrão neoliberal, a diferenciação espacial é um fenômeno crescente, com a reconstrução da fragmentação de espaços.

Na região Costa Oeste, a criação do Lago de Itaipu trouxe uma nova especificidade para os municípios que o margeiam. Além do alagamento de suas terras, esses municípios passaram a se articular para o desenvolvimento da atividade turística em âmbito regional. Conforme Souza (2008, p. 129):

\footnotetext{
A inundação de vasta área cria e define uma identidade regional, recriando as condições de existência. A nova região passa a ter na paisagem visual, em torno do lago, o elemento básico, segundo os governos, para ser explorada como atrativo turístico. A paisagem mercadoria, pelos seus "atrativos paisagísticos", passa a ser o motor da regionalização e de atividades que, para serem viáveis economicamente, devem contar com implementação de infraestrutura como forma de subsidiar o turismo.
}

Nesse contexto, cabe ressaltar a importância do recebimento dos royalties. Tal recurso torna-se importante para que ocorra o desenvolvimento 
integrado dos municípios lindeiros ao Lago de Itaipu, podendo ser investido em diversas áreas que visem ao desenvolvimento socioeconômico. Além dos royalties, recursos como o Fundo de Participação dos Municípios (FPM) e o Imposto sobre Circulação de Mercadorias e Serviços (ICMS) são importantes para garantir a qualidade de vida da população.

A estruturação do artigo está ordenada da seguinte maneira: além desta breve introdução, relacionam-se os royalties com o FPM e o ICMS, a seguir se discute o planejamento como instrumento de Ordenamento Territorial na perspectiva de se analisar os indicadores socioeconômicos do IDH , por último, as considerações finais.

\section{A relação dos royalties, FPM e ICMS}

Para amenizar os impactos causados pelo alagamento, são destinados recursos financeiros aos municípios afetados, proporcionalmente às suas áreas alagadas. Assim, o Brasil e o Paraguai passam a receber mensalmente a compensação financeira dos royalties, repasses que atingem a cifra anual de dezenas de milhões de dólares. No Brasil, os royalties são distribuídos entre Estados, União e aos municípios lindeiros ao Lago de Itaipu, que recebem $45 \%$ desses recursos.

A divisão do recurso entre esses municípios é realizada através de alguns critérios, como o repasse de recurso por ganho de energia, pela vazão e principalmente em virtude da área inundada com o lago, o que significa que, quanto maior a área inundada, maior o valor recebido pelos municípios em royalties (STERCHILE e SOUZA, 2008). Na Tabela 1 observa-se a área alagada de cada município, assim como a área total alagada na região Costa Oeste do Paraná: 
TABELA 1 - Área alagada $\left(\mathrm{km}^{2}\right)$ dos Municípios Lindeiros ao Lago de Itaipu.

\begin{tabular}{|l|c|l|c|}
\hline Município & Área Alagada & \multicolumn{1}{|c|}{ Município } & Área alagada \\
\hline Diamante D'Oeste & 5,62 & Missal & 40,07 \\
\hline Entre Rios do Oeste & 32,90 & Pato Bragado & 47,07 \\
\hline Foz do Iguaçu & 201,84 & Santa Helena & 263,76 \\
\hline Guaíra & 51,01 & Santa Terezinha de Itaipu & 41,90 \\
\hline Itaipulândia & 179,73 & São Miguel do Iguaçu & 90,91 \\
\hline Mal. Cdo. Rondon & 56,04 & São José das Palmeiras & 1,94 \\
\hline Medianeira & 1,16 & Terra Roxa & 1,58 \\
\hline Mercedes & 19,32 & & \\
\hline Total & & & $\mathbf{1 0 3 4 . 8 5} \mathbf{~ K m}^{\mathbf{2}}$ \\
\hline
\end{tabular}

FONTE: Itaipu Binacional

Observando os dados, verifica-se que a área total alagada é de aproximadamente $1034,85 \mathrm{Km}^{2}$, área superior ao tamanho do maior município da região, São Miguel do Iguaçu, que possui $849 \mathrm{~km}^{2}$ de área territorial, e que corresponde a quase o dobro do território de Guaíra $\left(568,8 \mathrm{~km}^{2}\right)$. Verifica-se, portanto, que os impactos foram significativos em termos de perda territorial. Já em relação aos municípios, Santa Helena foi aquele que teve a área mais atingida, seguido de Foz do Iguaçu e de Itaipulândia. No outro extremo, os municípios menos atingidos pelo lago foram Medianeira, Terra Roxa e São José das Palmeiras, o que significa que os recursos recebidos por esses municípios são inferiores àqueles primeiramente mencionados.

Os royalties contribuem para o aumento da receita da região Costa Oeste do Paraná e, conforme o Decreto Federal $n^{\circ} 1 / 91$, não devem ser aplicados no pagamento de dívidas e nem em pessoal permanente, devendo ser utilizados em infraestruturas que proporcionem o desenvolvimento social da população, aumentando sua qualidade de vida (RIBEIRO, 2005).

Tais recursos são de grande importância para a economia dos municípios, pois podem ser aplicados em diversas áreas, desde investimentos destinados ao turismo, até políticas e programas voltados a atender às expectativas dos cidadãos, em busca do desenvolvimento econômico e social para seus munícipes, garantindo, dessa forma, o desenvolvimento regional.

Conforme Souza (2008), com o recurso advindo dos royalties, os indicadores de qualidade de vida desses municípios deveriam ser excelentes, 
pois as administrações municipais dispõem de um maior volume de recursos para investirem em educação, agricultura, trabalho, saúde e obras de infraestrutura como estradas, redes de coleta e tratamento de esgoto, entre outros.

Além dos royalties, há outros recursos que são de grande importância para que as administrações públicas possam planejar e executar programas e ações com vista ao desenvolvimento social e econômico, tais como o FPM e o ICMS. Assim, conforme Sterchile \& Souza (2008, p. 15):

\begin{abstract}
A administração pública e seus investimentos são componentes importantes para o desenvolvimento econômico e social, principalmente a focalização do investimento público em infraestrutura, pois uma de suas características é que ela representa o conjunto de serviços básicos importantes para o desenvolvimento regional.
\end{abstract}

Recursos obtidos com o ICMS são repassados pelo estado aos municípios para que invistam nas áreas prioritárias. O valor dos repasses do ICMS leva em consideração os seguintes critérios: área geográfica, população, população dos cinquenta municípios mais populosos, educação, gasto com saúde, meio ambiente, patrimônio cultural, receita própria, cota mínima, municípios mineradores e compensação financeira por desmembramento de distrito (SALES E MORAES, 2011).

O FPM é repassado aos municípios de acordo com o tamanho de sua população. Assim, municípios com maior população recebem uma maior quantia de recursos, como é o caso de Foz de Iguaçu, seguido por Marechal Cândido Rondon e Medianeira, enquanto municípios menos populosos acabam recebendo um valor menos significativo do FPM:

\footnotetext{
A contagem populacional também é importante porque o número de habitantes influi no repasse de verbas, como o Imposto sobre Circulação de Mercadorias e Serviços (ICMS) e o Fundo de Participação dos Municípios (FPM). Os dados socioeconômicos refletem no repasse de recursos aos municípios, em diversos programas. (DIÁRIO POPULAR, 2008).
}

É através dos dados da população, obtidos com os censos demográficos que o governo planeja e destina verbas para setores importantes à população, como saúde, educação, habitação, etc. A seguir, na Tabela 2, é possível 
verificar os recursos provenientes dos royalties, assim como do FPM e o ICMS da região:

TABELA 2 - Recursos provenientes dos Royalties, FPM e ICMS - região Costa Oeste do Paraná.

\begin{tabular}{|c|c|c|c|c|}
\hline \multirow[t]{2}{*}{ MUNICÍPIOS } & \multirow{2}{*}{$\begin{array}{l}\text { Fundo de } \\
\text { Participação dos } \\
\text { Municípios } \\
\text { (FPM) (R\$) - } \\
2010\end{array}$} & \multicolumn{2}{|c|}{ Royalties* } & \multirow{2}{*}{$\begin{array}{r}\text { Imposto sobre } \\
\text { Circulação de } \\
\text { Mercadorias e } \\
\text { Serviços (ICMS) } \\
\text { (R\$) - 2010 }\end{array}$} \\
\hline & & $\begin{array}{r}\text { Repasse } \\
\text { Atual }(\mathrm{R} \$)\end{array}$ & $\begin{array}{r}\text { Acumulado } \\
(\mathrm{R} \$)\end{array}$ & \\
\hline $\begin{array}{l}\text { Diamante } \\
\text { D'Oeste }\end{array}$ & $4.045 .089,30$ & $38,2 \mathrm{mil}$ & 13,8 milhões & $27.680,75$ \\
\hline $\begin{array}{l}\text { Entre Rios do } \\
\text { Oeste }\end{array}$ & $4.045 .089,30$ & $236,4 \mathrm{mil}$ & 76,8 milhões & $227.278,23$ \\
\hline Foz do Iguaçu & $35.151 .388,11$ & 1,4 milhão & 499 milhões & $37.527 .123,92$ \\
\hline Guaíra & $9.438 .541,23$ & $366,5 \mathrm{mil}$ & 126 milhões & $2.442 .672,08$ \\
\hline Itaipulândia & $4.045 .089,30$ & 1,2 milhão & 420,3 milhões & $916.624,15$ \\
\hline $\begin{array}{l}\text { Marechal } \\
\text { Cândido Rondon }\end{array}$ & $13.483 .630,22$ & $402,5 \mathrm{mil}$ & 151,6 milhões & $8.586 .483,83$ \\
\hline Medianeira & $12.135 .267,10$ & $8,2 \mathrm{mil}$ & 2,7 milhões & $11.635 .342,19$ \\
\hline Mercedes & $4.045 .089,30$ & $138,7 \mathrm{mil}$ & 45 milhões & $313.735,83$ \\
\hline Missal & $5.393 .452,25$ & $288 \mathrm{mil}$ & 99 milhões & $467.158,00$ \\
\hline Pato Bragado & $4.045 .089,30$ & $338,1 \mathrm{mil}$ & 110 milhões & $131.671,37$ \\
\hline Santa Helena & $9.438 .541,23$ & 1,8 milhão & 652 milhões & $422.835,26$ \\
\hline $\begin{array}{l}\text { Santa Terezinha } \\
\text { de Itaipu }\end{array}$ & $8.090 .178,22$ & $301 \mathrm{mil}$ & 103,4 milhões & $1.316 .663,05$ \\
\hline $\begin{array}{l}\text { São José das } \\
\text { Palmeiras }\end{array}$ & $4.045 .089,30$ & $13,8 \mathrm{mil}$ & 4,6 milhões & $16.926,11$ \\
\hline $\begin{array}{l}\text { São Miguel do } \\
\text { Iguaçu }\end{array}$ & $9.438 .541,23$ & $653,1 \mathrm{mil}$ & 248,7 milhões & 2.617.418,20 \\
\hline Terra Roxa & $6.741 .815,22$ & $11,3 \mathrm{mil}$ & 3,8 milhões & $2.295 .134,02$ \\
\hline Total & $133.581 .890,61$ & 7,2 milhões & 2.5 bilhões & $68.944 .746,99$ \\
\hline
\end{tabular}

Fonte: Ipardes (2012); Itaipu Binacional - repasse de royalties 10 abril/2012. Organização: CASAGRANDE, A. E.

* Valor convertido em reais a partir da cotação do dólar comercial em 10/4/2012.

Analisando a receita total da região, que soma $R \$ 207,9$ milhões, constata-se que a maior parte dos recursos provém do FPM (R\$ 133 milhões) correspondendo 63,6\%, vindo em seguida o ICMS (R\$ 69 milhões) com 32,8\% e os royalties ( $R \$ 7$ milhões) com $3,43 \%$ da receita regional. Entre os municípios da região esses recursos distribuem-se de forma heterogênea. Em Santa Helena, município que teve uma área maior alagada pelo Lago de Itaipu, os royalties constituem cerca de $15,4 \%$ da receita total, o FPM constitui $80,9 \%$ 
e o ICMS apenas 3,6\% da receita total. Em Marechal Cândido Rondon, os royalties equivalem a $1,79 \%$ da receita total, enquanto o FPM e o ICMS representam, respectivamente, $60 \%$ e 38,2\%. Já no município de Medianeira, município que teve menor área alagada, os royalties constituem apenas 0,03\% da receita total, sendo que os maiores recursos advêm do FPM (51\%) e do ICMS (48,9\%). Assim, em municípios como Medianeira, os royalties não exercem grande influência, ao passo que, como em Santa Helena, os royalties têm grande importância, constituindo parte significativa da receita total.

Nesse sentido, os municípios da região Costa Oeste do Paraná, com recursos como o ICMS e FPM, somados aos royalties pagos pela Itaipu Binacional, teriam condições de garantir uma ótima qualidade de vida necessária para a sua população, se os recursos fossem destinados às áreas corretas, tais como saúde, educação, segurança, infraestrutura de estradas, tratamento de água e esgoto, entre outros.

Através desses recursos, é possível efetivar investimentos visando ao crescimento econômico aliado ao desenvolvimento socioeconômico dos municípios. Conforme salienta Sterchile \& Souza (2008), o crescimento econômico se dá mediante o aumento real de renda e o incremento na quantidade de bens e serviços. Assim, o crescimento econômico é dimensão relevante para o processo de desenvolvimento.

Diante dos dados apresentados, é preciso que os municípios da região Costa Oeste estejam articulados entre si para promover o planejamento regional, sabedores da importância deste instrumento para o ordenamento territorial.

\section{O Planejamento como instrumento de Ordenamento Territorial: análise do IDH}

Para a melhoria da qualidade de vida de sua população em conjunto com o crescimento econômico, é de extrema importância o ato de planejar, 
principalmente no que se refere às aplicações dos recursos públicos. Assim, segundo Souza (1994, p. 124), ao planejar:

O saber técnico, de um lado, e a experiência, as aspirações e os condicionantes psicossociais da população diretamente envolvida, de outro, não precisam entrar necessariamente em choque, devem antes enriquecer-se mutuamente. Para tanto, é necessário que os cidadãos comuns cujas vidas venham ser afetadas tenham garantidos o acesso às instâncias decisórias e o poder de deliberar, [...], superando dessa forma algumas das delimitações da democracia representativa.

O planejamento pode ser compreendido enquanto uma forma de ação do Estado sobre o território, demonstrando a prática do planejamento através de projetos e suas implicações sobre os espaços físicos e sociais, contribuindo para a consolidação de mudanças na dinâmica socioespacial. (TASCA, 2011). Conforme Casagrande \& Souza (2012, p. 6):

\begin{abstract}
O planejamento pode ser compreendido como uma ação estabelecida de desenvolvimento, em que, através de diagnósticos, como o recenseamento realizado pelo IBGE, da realidade de cada município ou região, são geradas políticas públicas para suprir a necessidade de cada local. Essas políticas são investidas em setores como saúde, educação, habitação, transportes, turismo, etc. Outra função do planejamento é promover o ordenamento e a gestão do território, com o objetivo de evitar elevados índices de concentração de renda e a intensificação da desigualdade social e da pobreza.
\end{abstract}

Nesse sentido, o planejamento, urbano e regional, torna-se uma estratégia de reordenamento do território, onde, segundo Becker (1991, p. 176):

\footnotetext{
O planejamento tornou-se o instrumento técnico e centralizado de intervenção estatal por ordenar o território segundo a política e a estratégia estabelecida. Por sua vez, a gestão das relações de poder necessárias para dirigir, no tempo e no espaço, a coerência das múltiplas finalidades, decisões e ações.
}

O ordenamento territorial se estabelece através de políticas de abrangência nacional, buscando um projeto nacional de desenvolvimento. Surge então a Política Nacional de Ordenamento Territorial (PNOT), no ano de 2003, coordenada pelo Ministério da Integração Nacional, buscando um uso 
harmonioso do território, visando ao desenvolvimento sustentável. Conforme Moraes (2005, p. 45):

\begin{abstract}
O ordenamento territorial diz respeito a uma visão macro do espaço, enfocando grandes conjuntos espaciais (biomas, macrorregiões, redes de cidades, etc) e espaços de interesse estratégico ou usos especiais (zona de fronteira, unidades de conservação, reservas indígenas, instalações militares, etc). Trata-se de uma escala de planejamento que aborda o território nacional em sua integridade, atentando para a densidade da ocupação, as redes instaladas e os sistemas de engenharia existentes (de transporte, comunicações, energia, etc). Interessam a ele as grandes aglomerações populacionais (com suas demandas e impactos) e os fundos territoriais (com suas potencialidades e vulnerabilidades), numa visão de contiguidade que se sobrepõe a qualquer manifestação pontual no território.
\end{abstract}

O ordenamento territorial atua como elemento de organização e de ampliação da racionalidade espacial das ações do Estado, sendo que, no caso do Brasil, a gestão territorial visa articular a política de ordenamento territorial com a política de desenvolvimento regional, devido ao seu gigantismo territorial e a necessidade de desconcentração da riqueza e população (RÜCKERT, 2007). Dentre as principais políticas que devem atuar no ordenamento territorial, destacam-se:

\begin{abstract}
[...] respeitar o meio ambiente, distribuir melhor as atividades agropecuárias modernas, as indústrias e serviços de ponta, diversificar as fontes de energia, favorecer o crescimento de cidades médias, todas essas ações contribuem para reequilibrar o território nacional. Em uma época cada vez mais reticular, repensar as redes de transporte de pessoas, mercadorias, energia e informação, montar uma malha menos voltada para o abastecimento do centro e mais equitativa será sem dúvida uma das alavancas mais poderosas para distribuir melhor o desenvolvimento entre as partes do país (RÜCKERT, 2007, p. 5).
\end{abstract}

Dentro da PNOT devem atuar planos nacionais, regionais e locais de ordenamento do território, neste último caso cabendo aos municípios promover o adequado ordenamento territorial urbano. De forma resumida, de acordo com Rückert (2007), os principais objetivos da PNOT são: o desenvolvimento socioeconômico equilibrado das regiões; a melhoria da qualidade de vida; a gestão responsável dos recursos naturais e a proteção do meio ambiente; e a utilização racional do território. 
Além disso, a PNOT deve estar em consonância com a política de parcerias sul-americanas, ampliando o ordenamento territorial para o conjunto do território sul-americano. Segundo Rückert (2007, p. 8):

A questão das relações bilaterais e multilaterais com os países vízinhos - isto é, os temas transfronteiriços - também fazem parte da pauta de uma política de ordenamento territorial no âmbito nacional, pois possuem importantes repercussões nos fluxos e mesmo em regiões às vezes distantes das fronteiras.

Nesse sentido, a região Costa Oeste do Paraná, situada na região fronteiriça, torna-se uma das regiões prioritárias para a atuação de políticas de ordenamento territorial. Ressalta-se que, para que a gestão do território ocorra de modo eficaz, a participação da população na formulação e na execução de políticas e de programas que atendam às suas necessidades, garantindo, assim, o bem-estar social da sociedade. Essas ações, políticas e programas, devem ser direcionadas à setores, já elencados anteriormente, como saúde, educação, habitação, transportes, etc., de forma a se promover o ordenamento e a gestão do território, e diminuir os índices de pobreza e desigualdade social.

Com o planejamento, é possível estabelecer um espaço urbano mais justo, onde todos os cidadãos tenham direito à cidade, legitimado pelo uso e ocupação do solo urbano, ao saneamento básico, à infraestrutura urbana, aos serviços públicos, ao acesso aos mercados de trabalho, ao lazer, entre outros.

Assim, o repasse dos royalties e de outros recursos contribui para as finanças dos municípios e para a ação do planejamento, mas se torna relevante que os gestores públicos, em conjunto com seus munícipes, discutam e definam as áreas em que será aplicado. É importante que os royalties sejam aplicados em programas e projetos que visem ao desenvolvimento local e regional aliado à qualidade de vida da população.

Há, no entanto, na realidade, municípios da região que carecem desses investimentos, com índices socioeconômicos baixos, como é o caso de Diamante D'Oeste e de São José das Palmeiras, que se encontram entre os municípios paranaenses com menores índices de desenvolvimento humano, conforme Tabela 3. 
TABELA 3 - Índice de Desenvolvimento Humano - Região Costa Oeste - 2000

\begin{tabular}{|c|c|c|c|c|c|c|c|c|c|c|c|}
\hline \multirow[t]{3}{*}{ Município } & \multicolumn{11}{|c|}{ Índice de Desenvolvimento Humano - IDH 2000} \\
\hline & \multirow{2}{*}{$\begin{array}{c}\mathrm{A}^{*} \\
\text { (anos) }\end{array}$} & \multirow{2}{*}{$\begin{array}{l}\mathrm{B}^{*} \\
(\%)\end{array}$} & \multirow{2}{*}{$\begin{array}{l}\mathrm{C}^{*} \\
(\%)\end{array}$} & \multirow{2}{*}{$\begin{array}{l}\mathrm{D}^{*} \\
(\mathrm{R} \$)\end{array}$} & \multirow[t]{2}{*}{$E^{*}$} & \multirow[t]{2}{*}{$\mathrm{F}^{*}$} & \multirow{2}{*}{$\mathrm{G}^{*}$} & \multicolumn{2}{|c|}{$\mathbf{H}^{*}$} & \multirow[t]{2}{*}{$I^{*}$} & \multirow[t]{2}{*}{$\mathrm{J}^{*}$} \\
\hline & & & & & & & & 1991 & 2000 & & \\
\hline $\begin{array}{l}\text { Diamante } \\
\text { D'Oeste }\end{array}$ & 68,31 & 79,41 & 78,66 & 153,64 & 0,722 & 0,792 & 0,613 & 0,608 & 0,709 & 307 & 2.835 \\
\hline $\begin{array}{l}\text { Entre Rios } \\
\text { do Oeste }\end{array}$ & 77 & 96,33 & 84,39 & 337,95 & 0,872 & 0,923 & 0,745 & 0,755 & 0,847 & 4 & 41 \\
\hline $\begin{array}{l}\text { Foz do } \\
\text { Iguaçu }\end{array}$ & 68,28 & 92,52 & 86,46 & 326,19 & 0,721 & 0,905 & 0,739 & 0,722 & 0,788 & 42 & 850 \\
\hline Guaíra & 71,14 & 87,42 & 85,43 & 250,68 & 0,769 & 0,868 & 0,695 & 0,709 & 0,777 & 69 & 1.125 \\
\hline Itaipulândia & 68,28 & 90,37 & 82,78 & 229,13 & 0,721 & 0,878 & 0,680 & 0,691 & 0,760 & 129 & 1.583 \\
\hline $\begin{array}{l}\text { Marechal } \\
\text { Cândido } \\
\text { Rondon }\end{array}$ & 73,48 & 95,66 & 88,16 & 341,71 & 0,808 & 0,932 & 0,747 & 0,758 & 0,829 & 8 & 139 \\
\hline Medianeira & 68,28 & 92,83 & 85,45 & 277,50 & 0,721 & 0,904 & 0,712 & 0,730 & 0,779 & 67 & 1.081 \\
\hline Mercedes & 74,05 & 93,42 & 77,11 & 349,05 & 0,818 & 0,880 & 0,750 & 0,725 & 0,816 & 13 & 284 \\
\hline Missal & 72,17 & 92,23 & 85,03 & 237,91 & 0,786 & 0,898 & 0,686 & 0,722 & 0,790 & 39 & 800 \\
\hline $\begin{array}{l}\text { Pato } \\
\text { Bragado }\end{array}$ & 75 & 94,74 & 83,61 & 292,17 & 0,833 & 0,910 & 0,720 & 0,733 & 0,821 & 11 & 219 \\
\hline $\begin{array}{l}\text { Santa } \\
\text { Helena }\end{array}$ & 72,36 & 91,25 & 90,33 & 256,81 & 0,789 & 0,909 & 0,699 & 0,726 & 0,799 & 25 & 586 \\
\hline $\begin{array}{l}\text { Santa } \\
\text { Terezinha } \\
\text { de Itaipu }\end{array}$ & 70,04 & 90,31 & 83,09 & 265,26 & 0,751 & 0,879 & 0,704 & 0,689 & 0,778 & 68 & 1.103 \\
\hline $\begin{array}{l}\text { São José } \\
\text { das } \\
\text { Palmeiras }\end{array}$ & 71,01 & 77,54 & 83,27 & 150,67 & 0,767 & 0,794 & 0,610 & 0,650 & 0,724 & 259 & 2.539 \\
\hline $\begin{array}{l}\text { São Miguel } \\
\text { do Iguaçu }\end{array}$ & 68,50 & 89,52 & 86,22 & 307,73 & 0,725 & 0,884 & 0,729 & 0,701 & 0,779 & 66 & 1.080 \\
\hline Terra Roxa & 72,36 & 85,63 & 80,96 & 204,68 & 0,789 & 0,841 & 0,661 & 0,683 & 0,764 & 105 & 1479 \\
\hline
\end{tabular}

Fonte: Atlas do Desenvolvimento Humano no Brasil - PNUD, IPEA/Ipardes, 2010. Organização:

CASAGRANDE, A.E.

A* Esperança de vida ao nascer

$\mathrm{B}^{*}$ Taxa de alfabetização de adultos

C* Taxa bruta de frequência escolar

$\mathrm{F}^{*}$ Educação (IDH-E)

$\mathrm{G}^{*}$ Renda (IDHM-R)

H* IDH-M (2000 e 1991)

D* Renda per capita nacional

I* Classificação na unidade da federação

E* Longevidade (IDH-L)

$\mathrm{J} *$ Classificação no país.

Quando se refere ao Índice de Desenvolvimento Humano Municipal (IDH-M), os critérios utilizados para essa avaliação são os mesmos utilizados no IDH de um país, mas alguns dos indicadores utilizados são diferentes. Em relação à educação, o cálculo do IDH-M leva em consideração a taxa de alfabetização de pessoas acima dos quinze anos de idade e a taxa bruta de frequência escolar, onde se somam as pessoas que frequentam o curso fundamental, médio e superior, dividindo pela população na faixa etária de 7 a 22 anos de idade. Em relação à expectativa de vida, analisam-se as condições 
de saúde e de salubridade de cada localidade, de modo que, quanto mais mortes houver nas faixas etárias mais precoces, menor será a expectativa de vida do local. Em relação à renda, o critério utilizado é a renda municipal per capita, onde se soma a renda de todos os residentes e divide-se o resultado pelo número de pessoas que moram no município. Esses componentes de análise do IDH-M são transformados em índices que variam de 0 (pior) a 1 (melhor), indicando o nível de desenvolvimento humano de cada município.

É importante notar que o IDH-M realizado nos municípios brasileiros utiliza como fonte de dados os do censo demográfico, e que, portanto, também é realizado a cada dez anos, após a apuração dos dados do censo. Assim, no momento de realização desta pesquisa, o IDH-M de 2010 ainda não se encontrava disponível. Por essa razão trabalhamos com os dados referentes ao IDH-M do ano de 2000.

Observando os dados da tabela 3 é possível constatar que o IDH-M na região Costa Oeste é relativamente alto. Em relação ao IDH-M do ano de 1991, verifica-se que todos os municípios aumentaram sua classificação, de forma que podemos constatar que houve um aumento na qualidade de vida entre 1990 e 2000.

Em relação ao Índice de Desenvolvimento Humano de 2000, há municípios que se destacam, como Entre Rios do Oeste e Marechal Cândido Rondon, que ocupam respectivamente a $4^{\circ}$ e a $8^{\circ}$ posição entre os municípios paranaenses. Já os municípios da região com menor IDH-M são Diamante D'Oeste $(0,709)$ e São José das Palmeiras $(0,724)$, que ocupam, respectivamente, as posições $307^{\circ}$ e $259^{\circ}$ em relação aos 399 municípios paranaenses. Em seguida vêm Terra Roxa $(0,764)$ e Itaipulândia $(0,760)$, ocupando as posições $105^{\circ}$ e $129^{\circ}$.

Comparando esses dados com o IDH do Paraná $(0,787)$ e do Brasil $(0,766)$, percebe-se que a maior parte dos municípios da região está acima da média nacional e estadual, o que indica que a região possui importância no que se refere à qualidade de vida.

Ainda na Tabela 3, é possível analisar outras variáveis que são a base do IDH, tais como esperança de vida ao nascer, educação, renda, etc. Em 
relação à educação, através dos índices de alfabetização e frequência escolar, percebe-se que a maioria dos municípios tem mais de $90 \%$ de sua população adulta alfabetizada (pessoas acima de quinze anos de idade), o que indica que a maior parte da população da região tem, pelo menos, acesso às oito séries do ensino fundamental.

A educação é muito importante, pois é um dos parâmetros básicos do desenvolvimento econômico e social, trazendo consigo reflexos sobre a produtividade e a evolução do mercado de trabalho, tendo implicações significativas sobre a saúde, fecundidade e outros temas sociais (IBGE, 2010). Observando o Gráfico 1, percebe-se que a região Costa Oeste possui uma taxa de alfabetização considerável:

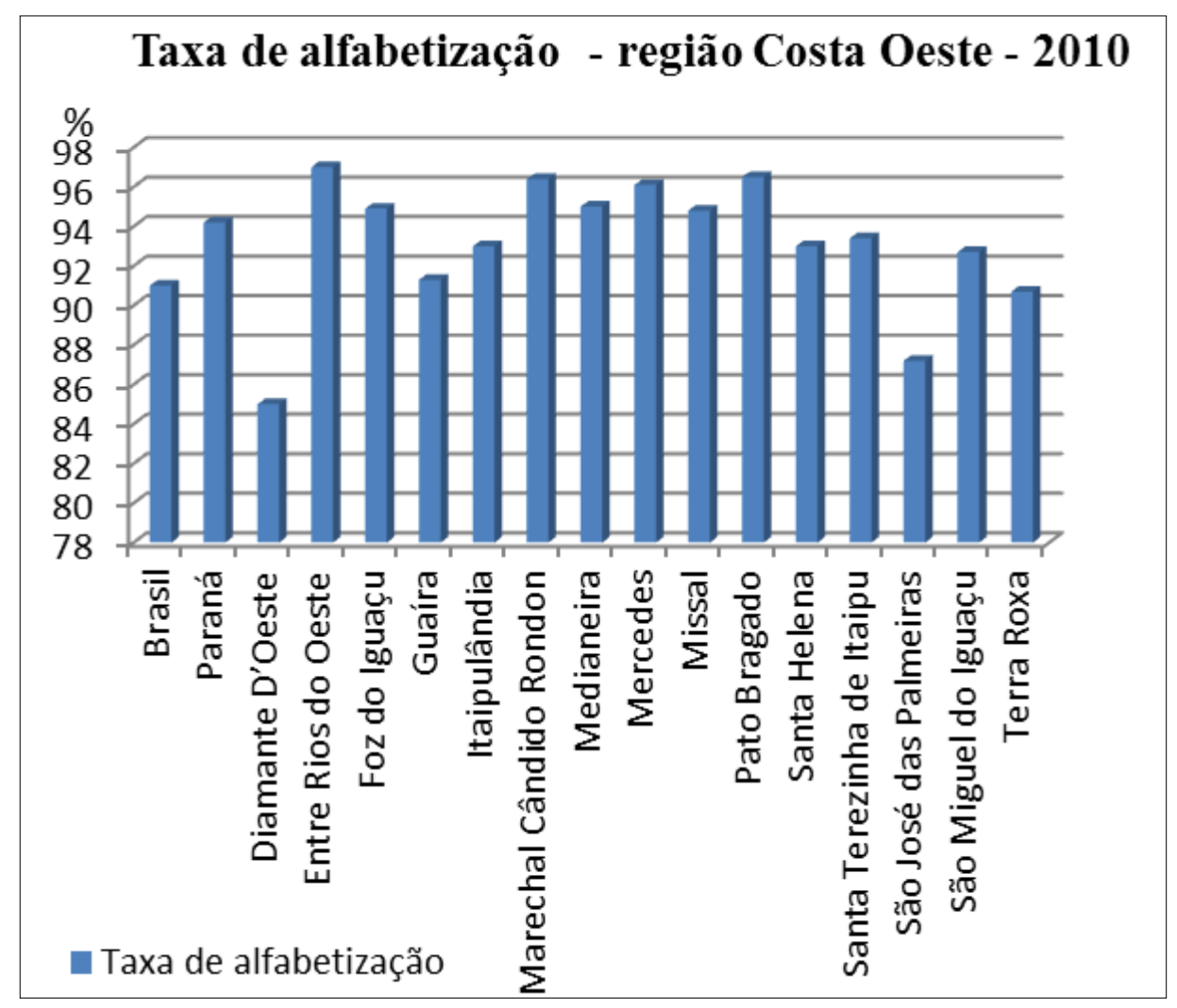

Gráfico 1 - Taxa de alfabetização de pessoas de 10 anos ou mais de idade Região Costa Oeste do Paraná - 2010.

Fonte: IBGE, Censo Demográfico 2010. Elaboração: Casagrande, A. E.

O que se observa, é que a maioria dos municípios possuem a taxa de alfabetização acima dos 90\%, com exceção dos municípios de Diamante D'Oeste e São José das Palmeiras. Coincidentemente, esses são os dois 
municípios da região com os menores índices de desenvolvimento humano (IDH-M).

Em relação à expectativa de vida, a média da região Costa Oeste ficou em torno de 71,3 anos no ano de 2000 , enquanto a expectativa de vida no Brasil é de 73,4 anos (IBGE, 2010).

Esses índices de qualidade de vida poderiam, no entanto, ser muito melhores, principalmente considerando que esses municípios recebem grandes montantes de recursos provenientes dos royalties. Só a título de comparação, temos o município de Quatro Pontes, município também desmembrado de Marechal Cândido Rondon, no ano de 1991 (além dos municípios de Mercedes, Entre Rios do Oeste e Pato Bragado). Em 2000, Quatro Pontes encontrava-se na posição de segundo município do Paraná com os melhores índices de desenvolvimento humano. É importante ressaltar que esse município não recebe recursos dos royalties, uma vez que não teve suas terras atingidas pelo Lago de Itaipu.

Em relação à Entre Rios do Oeste e Marechal Cândido Rondon, que se destacam no IDH-M, quando comparados esses dados com os royalties recebidos, há municípios que acumulam valores muito maiores, mas que se distanciam largamente do desenvolvimento social apontado nesses municípios. Compreende-se que não basta haver o recurso dos royalties, é necessário que o recurso seja aplicado visando o desenvolvimento do município, o bem-estar da população. Segundo Ribeiro (2005, p. 38):

\footnotetext{
[...] parece haver uma ruptura daquilo que se prega como igualdade social e a devida aplicação dos royalties, pois, enquanto alguns poucos municípios lideram o ranking estadual do IDH (Entre Rios do Oeste e Marechal Cândido Rondon), outros, se não ocupam as últimas colocações estão próximos dela (Diamante do Oeste).
}

O que se pode constatar é que os royalties não são aplicados visando o atendimento à população, como saúde e educação. É claro que o investimento em infraestrutura é importante para o desenvolvimento dos municípios. Verifica-se que o discurso da aplicação dos royalties se distancia da realidade, onde sua aplicação tem sido ocultada, pois não há uma transparência de informação perante a população do município. 
Mesmo dispondo de um volume maior de recursos para serem destinados em educação, agricultura, trabalho, saúde, obras de infraestrutura, redes de coleta e tratamento de esgoto, a realidade mostra que a aplicação desses recursos não foi distribuída de maneira satisfatória para toda a população.

Com essas desigualdades verificadas entre o grau de desenvolvimento humano, pode-se compreender que, muitas vezes, o discurso do desenvolvimento regional não está posto em prática, uma vez que se verifica a dificuldade de integração entre os municípios, assim como uma desigualdade entre eles quanto ao grau de desenvolvimento.

Ressalva-se que os recursos provenientes dos royalties se encerrarão em 2023, segundo o Tratado de Itaipu, e que os municípios devem estar preparados para o fim dessas receitas. Ocorre, no entanto, que os municípios lindeiros ao Lago de Itaipu entraram com um pedido de manutenção do repasse dos royalties após o prazo estimado, e o fizeram com a afirmação de que "[...] a compensação financeira recebida mensalmente representa, para os gestores públicos lindeiros, a garantia de efetivar políticas públicas direcionadas, principalmente, ao bem-estar do cidadão e ao meio ambiente" (LINDEIROS, 2010).

No caso de Marechal Cândido Rondon, o fim dos royalties não trará grandes impactos para a economia, uma vez que o município é bem desenvolvido no setor industrial, agrícola e comercial. Por outro lado, há municípios pequenos, que, mesmo com a compensação financeira, apresentam índices baixos de qualidade de vida. A questão central é: $\square$ Como ficará a situação desses pequenos municípios com o fim do recebimento dos royalties?

Uma estratégia que pode ser utilizada por esses municípios é a da integração, definindo em conjunto políticas e programas comuns na busca do desenvolvimento regional, possibilitando dessa maneira a ampliação da oferta de serviços, utilização conjunta de equipamentos, cooperação técnica e realização conjunta de obras, etc., o que garantiria o seu desenvolvimento econômico conjunto, por meio do planejamento regional. 


\section{CONSIDERAÇÕES FINAIS}

Através deste estudo, procurou-se destacar a importância do planejamento e do ordenamento territorial para o desenvolvimento da região Costa Oeste do Paraná, considerando as suas especificidades, como as transformações ocorridas em seu território nas últimas décadas, além de sua localização na faixa de fronteira.

Neste contexto, foram analisados os principais recursos obtidos pela região, como os royalties pagos pela Usina Hidrelétrica de Itaipu, o Fundo de Participação dos Municípios e o Imposto sobre Circulação de Mercadorias e Serviços, verificando a sua distribuição entre os municípios da região.

Além disso, discutiu-se se estes recursos são aplicados em áreas prioritárias, como saúde, educação, segurança, infraestrutura etc., com o objetivo de garantir a qualidade de vida de sua população. Para isso, foi analisado o Índice de Desenvolvimento Humano Municipal.

Verificou-se que o IDH-M da maior parte dos municípios da região é alto, superando o índice estadual e nacional. No entanto, constataram-se disparidades entre os municípios, onde há aqueles que se destacam (Entre Rios do Oeste e Marechal Cândido Rondon) e aqueles com indicadores baixos de desenvolvimento humano (Diamante D'Oeste e São José das Palmeiras).

Considerando que estes municípios recebem recursos provenientes dos royalties, conclui-se que estes indicadores poderiam ser melhores, se realmente os recursos fossem aplicados visando ao atendimento das demandas da população. Nesse sentido, destaca-se a importância do planejamento e do ordenamento territorial, que deveriam, na prática, garantir a aplicação dos recursos em áreas que visem à melhoria da qualidade de vida nos municípios, promovendo a gestão do território, reduzindo os índices de desigualdade social, assegurando o desenvolvimento em âmbito regional.

\section{REFERÊNCIAS BIBLIOGRÁFICAS}

BARROS, M. J. B. Especificidades da gestão do território regional: as políticas públicas da Região Tocantins segundo o Planejamento Territorial Participativo 
do Pará 2008-2011. XIV Encontro Nacional da ANPUR. Rio de Janeiro, maio de 2011.

BECKER, Bertha K. Geografia Política e Gestão do Território no limiar do século XXI: uma representação a partir do Brasil. Revista Brasileira de Geografia. Rio de Janeiro, 53(3): jul./set., 1991.

CASAGRANDE, A. E. Evolução dos censos demográficos (1991, 2000 e 2010) e indicativos socioeconômicos na região Costa Oeste do Paraná. Marechal Cândido Rondon, 2011. Monografia em Geografia. Universidade Estadual do Oeste do Paraná.

CASAGRANDE, A E.; SOUZA, E. B. C de. O espaço e a demografia: o planejamento regional em perspectiva nas margens paranaenses do Lago de Itaipu. Revista Sociedade e Território. Natal, v. 24, n. 1, p. 2-27, jan/jun. 2012.

DIÁRIO POPULAR. A importância do censo demográfico. Disponível em: < http://www.diariopopular.com.br/site/content/home/ >. Acesso em: 7 jan. 2011.

HAESBAERT, R. Região: trajetos e perspectivas. Trabalho apresentado na Primeira Jornada de Economia Regional Comparada, FEE-RS, Porto Alegre, 2005.

HAESBAERT, R. Região, diversidade territorial e globalização. GEOgraphia, Ano 1, $\mathrm{n}^{\circ}$ 1. 1999.

IBGE. Por que fazer o censo de 2010?. Diretorias de Pesquisas, 2010. Disponível em: < http://www.ibge.com.br/home/ >. Acesso em: 31 mar. 2011

LINDEIROS fecham 2010 com pedido de manutenção dos royalties. Portal Rondon 15/12/2010. Disponível em: <http://portalrondon.com.br/ noticias/zoom/ lindeiros+fecham $+2010+$ com+pedido+de+manutencao+dos+royalties/1837>. Acesso em: 22 ago. 2011.

MORAES, A. C. R. Ordenamento Territorial: uma conceituação para o planejamento estratégico. Para pensar uma política nacional de ordenamento territorial. Ministério da Integração Nacional, 2005, p. 43-47.

OLIVEIRA, L. C. de. Economia, instituições e os royalties: o caso dos municípios lindeiros ao lado de Itaipu Binacional no oeste paranaense. Toledo, 2008. Dissertação de Mestrado. Universidade Estadual do Oeste do Paraná.

RIBEIRO, Â. M. B. Planejamento turístico regional: um estudo da região Costa Oeste do Paraná. Toledo, 2005. Dissertação de Mestrado. Universidade Estadual do Oeste do Paraná. 
RÜCKERT, A. A. A Política Nacional de Ordenamento Territorial, Brasil. Uma política territorial contemporânea em construção. Revista Electrónica de Geografia y Ciencias Sociales. ago. 2007.

SALES. A. A. M.; MORAES, F. B de. Política(s) de descentralização de redistribuição de recursos: O ICMS patrimônio cultural em Minas Gerais. XIV Encontro Nacional da ANPUR. Rio de Janeiro, maio de 2011.

SOUZA, E. B. C. de. Políticas territoriais de desenvolvimento regional: o planejamento em foco nas margens do Lago de Itaipu - Costa Oeste do Paraná. Revista Paranaense de Desenvolvimento, Curitiba: Ipardes, n. 115, p. 125-147, jul./dez. 2008.

SOUZA, M. J. L. de. Planejamento integrado e desenvolvimento: natureza, validade e limites. Revista Terra Livre. n. 10, 1994.

STERCHILE S. P. W.; SOUZA, E. B. C. de. Apontamentos sobre a aplicação dos royalties da Itaipu Binacional e o processo de desenvolvimento. Revista Brasileira de Gestão e Desenvolvimento Regional, v. 4, n. 2, p. 3-22, maio/ago. 2008.

TASCA, L. et alii. Projetos urbanos em cidades médias: a implantação de um shopping em Juiz de Fora, MG. XIV Encontro Nacional da ANPUR. Rio de Janeiro, maio de 2011.

TRATATO DE ITAIPU. Disponível em: < http://www.itaipu.gov.br/sites/default/files/u13/tratadoitaipu.pdf $\geq$. Acesso em: 23 maio 2012. 